\title{
MEASURING CUSTOMER SATISFACTION IN TURK TELEKOM COMPANY USING STRUCTURAL EQUATION MODELING TECHNIQUE
}

\author{
*Selim ZAIM \\ *Ali TURKYILMAZ \\ **Mehves TARIM \\ ***Bilal UCAR \\ *Oguz AKKAS \\ *Fatih University, Turkey \\ **Marmara University, Turkey \\ ***Turk Telekom, Turkey
}

\begin{abstract}
Customer satisfaction and loyalty are key issues for organizations in today's competitive market place. Customer satisfaction index models are developed and put into practice as models to measure customer satisfaction at institutional, industrial and national basis. In this project, European Customer Satisfaction Model was taken as the reference and Turk Telekom Customer Satisfaction Model was acquired.
\end{abstract}

Keywords :Customer Satisfaction,Turk Telecom, Structural Equation Modeling

\section{INTRODUCTION}

The concept of customer satisfaction has attracted much attention in recent years. To improve product and service quality, and maintain customer loyalty within a highly competitive marketplace it became a central concern for companies and organizations. A key motivation for the growing emphasis on customer satisfaction is that high customer satisfaction lead to a stronger competitive position resulting in higher market share and profit (Fornell, 1992). Customer satisfaction is also generally assumed to be a significant determinant of repeat sales, positive word-of-mouth, and customer loyalty (CL). Satisfied customers return and buy more, and they tell other people about their experiences (Fornell, et al., 1996).Until recently in most countries, telecommunications service providers were state owned, state operated, and often monopolistic. With the privatization of British Telecom and the introduction of competition in the U.S. long-distance telephone services, the late 1980s and 1990s witnessed the most dramatic policy changes the telecommunications world had ever seen. The monopoly-based system of service provision, which dominated the world's telecommunications markets for over three-quarters of the last century, gave way to more competitive supply in many markets. (Li and $\mathrm{Xu}, 2004$ )

There have been two major growth areas in telecommunications over the past two years in the OECD - mobile and broadband. This growth has resulted in the number of mobile and broadband subscribers as percentage of all telecommunications subscriptions or "access paths" accounting for $74 \%$ of all communications path in 2007. Mobile alone accounts for $61 \%$ while standard phone lines only account for $26 \%$. This is a dramatic shift from the year 2000 when there were more fixed line access paths (51\%) than mobile. The number of fixed analogue lines across the OECD fell by 37 million between 2005 and 2007 but the growth of broadband lines and mobile subscribers (77 million and 201 million respectively) over the same period more than compensated for the fixed line losses. The penetration rate for fixed telephone lines in 2007 was 41 subscribers per 100 inhabitants, which was less than the penetration rate ten years earlier. Overall, the penetration rate rose from $43 \%$ in 1996 to a maximum of $47 \%$ in 2000, only to decline again to $41 \%$ in 2007. (OECD, 2009)

There has been an impressive shift away from dial-up fixed internet connections to broadband. In 2005, dial-up connections still accounted for $40 \%$ of fixed internet connections. Just two years later that percentage fell to $10 \%$. Broadband now is the dominant fixed access method in all OECD countries. Broadband subscriptions reached 251 million in June 2008, growing an average of $20 \%$ be- 
tween 2005 and 2007 compounded annually. The number of broadband subscriptions corresponds to 21.2 subscribers per 100 inhabitants in the OECD. (OECD, 2009)

Turkish electronic communications market has developed rapidly since liberalization on 1st January 2004. The number of players in the market tended to increase continuously after liberalization. By the end of 2008 there exist 256 operators in the electronic communications market (ICTA, 2010).

Turk Telekom group (the leader of the telecommunication sector in Turkey) provides integrated telecommunication services from PSTN (fixed line telephone service), GSM (Global System for Mobile Communications) to broadband internet. Turk Telekom group companies have 16.8 millions of PSTN customers, 6 millions of broadband internet customers and 12.1 million GSM customers as of September 30, 2009. The privatization of Turk Telekom was closed on November 2005 (Turk Telekom, 2010).

Fixed (incumbent and long distance telephony service providers) and mobile operators' total sales revenues which constitute the most important part in total electronic communications sector revenues are shown in the Figure 1. From the beginning of liberalization process in 2004 to 2007, total revenues continuously increased. However in 2008 sales revenues decreased by 5\% to 19.3 billion TL which was 20.3 billion TL in 2007. After a continuous increase, in 2008, the share of mobile

Table 1. Fixed and mobile operators' total sales revenues

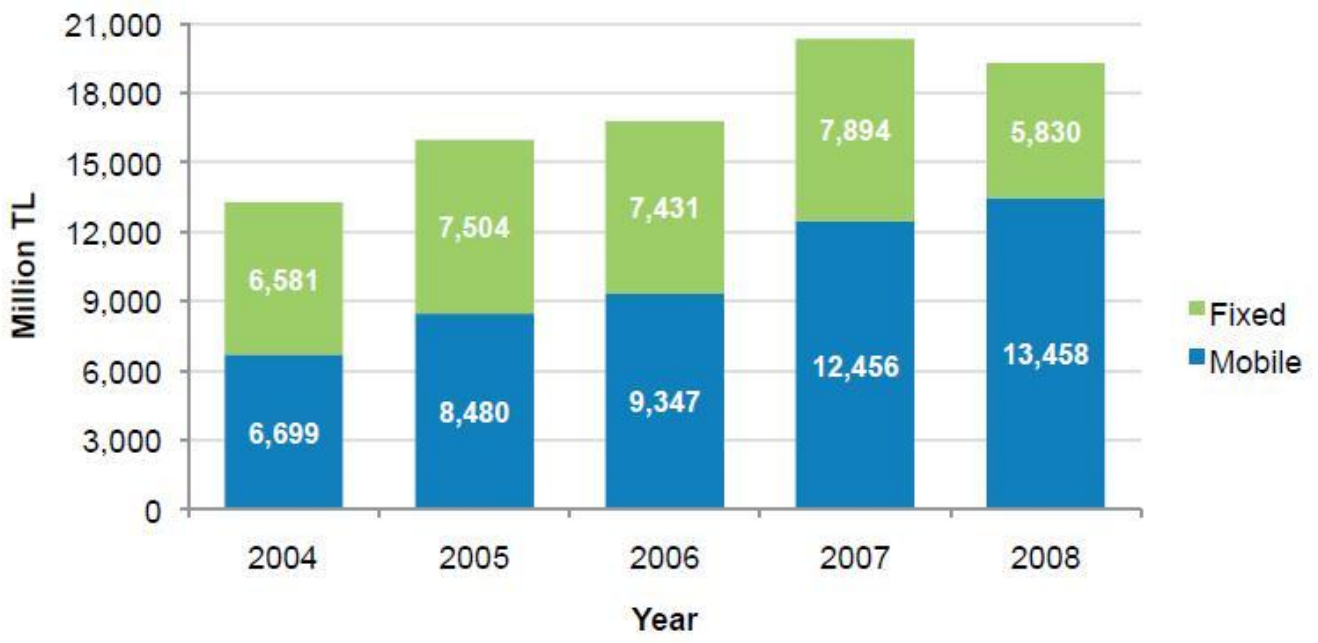

operators in total revenues became 70\% and fixed operators' share decreased to 30\% (ICTA, 2010).

Fixed line penetration rate, which has reached its peak in 2001 (28.5\%) is in a slightly decreasing trend especially starting from 2004 due to mobile telephony usage. The number of fixed subscribers decreased to 17.5 million in 2008 corresponding to a penetration rate of $24.5 \%$. (ICTA, 2010)

Regardless of technology and communication infrastructures they use, Long Distance Telephony Services (LDTS) operators can provide intercity and/or international telephony services to the end users as alternatives to Turk Telekom. LDTS operators reached a share of $13 \%$ in 2008. (ICTA, 2010)

Competition in the broadband internet services market is developing. By the end of 2008 number of internet subscribers in Turkey reached up to almost 6 million. After the opening up of ADSL and G.SHDSL ports of incumbent operator (Turk Telekom) to the use of ISPs, resale of broadband access services commenced. On the other hand, ISPs started to access to Turk Telekom's infrastructure for the provision of broadband services via bit stream access. (ICTA, 2010)

Market shares of incumbent operators in retail broadband services market in EU countries are given in Figure 2. Incumbent operators' average share in broadband market is $46 \%$ in EU countries, whereas Turk Telekom has 93\% market share in Turkey (ICTA, 2010). 


\section{Table 2. Shares of Incumbents and Alternative Operators in Retail Broadband Services in Turkey and Some EU countries, (\%)}

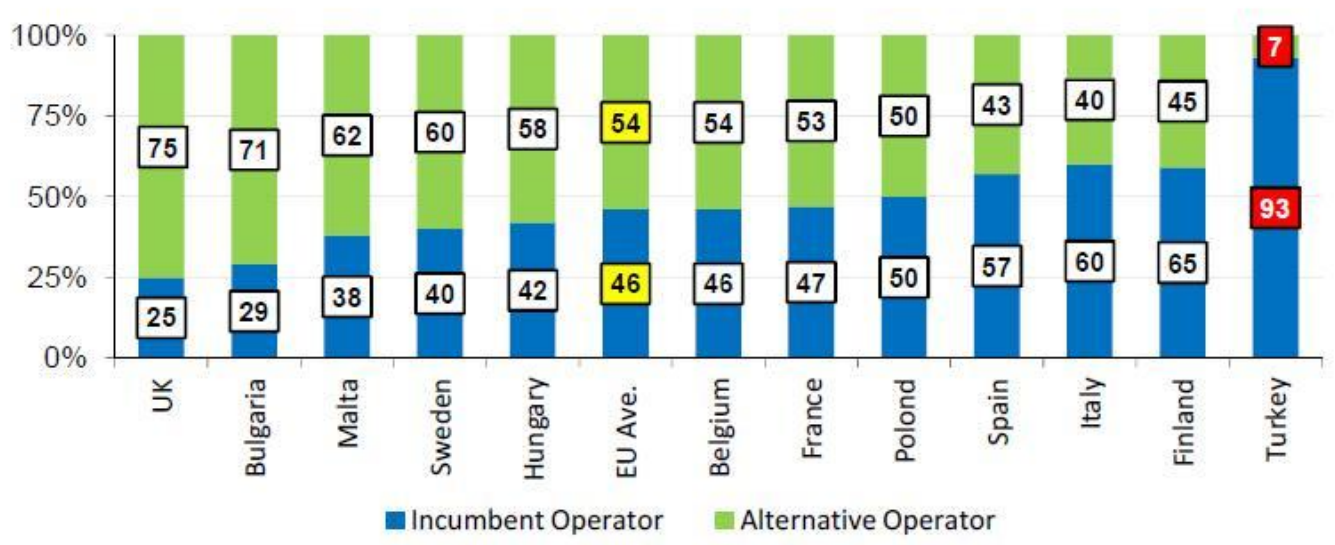

The purpose of this paper is to provide information about the customer satisfaction indices (CSIs) and show the results of a CSI study carried out in Turkish telecommunication sector. The rest of this paper is structured as follows: the second section briefly presents an overview of the CSIs and their developments in different countries. In the third section, the ECSI model implemented in Turkish telecommunication sector is described. The methodology and data analysis are discussed in the fourth section, followed by the analysis of the main results. Discussions and concluding remarks are provided at the end.

\section{LITERATURE REVIEW ABOUT CUSTOMER SATISFACTION INDEX (CSI) MODEL}

The original interest in customer satisfaction research was on customer's experience with a product episode or service encounter (Anderson et al., 1994). More recent studies have focused on cumulative satisfaction. Cumulative satisfaction defines satisfaction as customer's overall experience to date with a product or service provider. This approach to satisfaction provides a more direct and comprehensive measure of a customer's consumption utility, subsequent behaviors and economic performance (Fornell et al., 1996). The ECSIs were built upon a cumulative view of satisfaction.

The ECSI model is a structural model based on the assumptions that customer satisfaction is caused by some factors such as perceived quality (PQ), perceived value (PV), expectations of customers, and image of a firm. These factors are the antecedents of overall customer satisfaction. The model also estimates the results when a customer is satisfied or not. These results of customer satisfaction are consequences factors such as complaints or loyalty of customer (Johnson et al., 2001). Each factor in the ECSI model is a latent construct which is operationalized by multiple indicators (Fornell, 1992; Chien et al., 2002).

Swedish customer satisfaction barometer (SCSB), reported in 1989, was the first national CSI (Fornell, 1992). It was applied to 130 companies from 32 Swedish industries. In 1992, the German customer barometer was introduced. The study is conducted for 52 industry sectors in Germany (Meyer and Dornach, 1996). The American customer satisfaction index (ACSI) was developed in 1993 by Claes Fornell, Founder of SCSB. The ACSI survey is conducted for seven main economic sectors, 35 industries, and more than 200 companies with revenues totaling nearly 40 percent of the US GNP (Fornell et al., 1996). The European customer satisfaction index (ECSI), developed by European organization for quality and European foundation for quality management, was first introduced in 1999 across 11 European countries (Eklöf and Westlund, 2002). Other efforts for establishing national CSIs can be seen in Denmark, Austria, France, Netherlands, Switzerland, Taiwan, New Zealand, South Korea, Malaysia, Hong Kong and Russia (Grigoroudis and Siskos, 2003).

The original SCSB model contains two primary antecedents of satisfaction: perceived performance 
and customer expectations. These both antecedents are expected to have a positive effect on satisfaction. The consequences of satisfaction in the SCSB model are derived from Hirschman's (1970) exitvoice theory which describes the results of dissatisfaction. The customer either exits (stops buying from the firm), or voices its complaint to the firm in an effort to receive restitution. It is expected that an increase in satisfaction should decrease complaints and increase CL (Fornell, 1992; Anderson et al., 1994).

The ACSI model builds upon the original SCSB model specifications adapted in the distinct characteristics of the US economy. The main differences between the original SCSB model and the ACSI model are the addition of a PQ component, as distinct from PV, and the addition of measures for customer expectations. The ACSI model predicts that as both PV and PQ increase, customer satisfaction should also increase (Anderson et al., 1994). For the consequences, as in the SCSB, it is expected that when customer satisfaction increase then loyalty increase and complaints decrease (Fornell et al., 1996).

The ECSI, a modified adaptation of the ACSI model, considers the European economy as a whole, and thus, CSI scores of the countries can be compared with each other and with the European average (Eklöf and Westlund, 2002). In the ECSI model, customer expectations, PQ, PV, customer satisfaction, and CL constructs are modeled the same as in the ACSI. There are two fundamental differences between the ACSI and ECSI models. First, the ECSI model does not include the complaint behavior construct as a consequence of satisfaction. Second, the ECSI model incorporates company image as a latent variable in the model. In the ECSI model, company image is expected to have a direct effect on customer expectations, satisfaction and loyalty (Grigoroudis and Siskos, 2003).

The first studies on CSI model in Turkey were the research studies done by Turkyilmaz and Ozkan (2004) and Aydin and Ozer (2005). Aydin and Ozer (2005) developed and tested a new model for Turkish global system for mobile (GSM) users. The structural model they used includes some new constructs, such as switching cost, trust, and complaint handling. They collected the data from 1,662 GSM users in four Turkish cities using a face-to-face survey. In their study, the model is estimated using maximum likelihood (ML)-based covariance structure analysis method namely LISREL.

Then the first national model, Turkish customer satisfaction index (TCSI), was reported as a pilot study in the fourth quarter of 2005 by Turkish Quality Association (Kal-Der) and KA Research Limited. Since, the measurement model of the TCSI is same as the ACSI model, it includes customer expectations, PQ, PV, customer satisfaction, CL and customer complaints constructs. In 2006, the TCSI was implemented for 100 companies from 25 sectors (TMME, 2006).

\section{THE CSI MODEL AND RESEARCH HYPOTHESES}

The Customer Satisfaction Index (CSI) is an economic indicator that measures customer satisfaction. A model has been derived specifically for the CSI. In this model, six interrelated latent variables are introduced. It is based on well-established theories and approaches in customer behavior and it is to be applicable for a number of different industries.

The CSI model is described in Figure 3. A set of manifest variables is associated with each of the latent variables. This structure is called the CSI model.

The image construct evaluates the underlying image of the company. Image refers to the brand name and the kind of associations customers get from the product/company (Andreassen and Lindestad, 1998). Martensen et al. (2000) indicates that image is an important component of the customer satisfaction model. For the companies, image is a result of being reliable, professional and innovative, having contributions to society, and adding prestige to its user. It is expected that image has a positive effect on customer expectations, customer satisfaction and loyalty.

\section{Customer Expectations}

Expectations are the results of prior experience with the company's products. This construct evaluates customer expectations for overall quality, for product and service quality, and for fulfillment of 
personal needs. Customer expectations construct is expected to have a direct and positive relationship with customer satisfaction (Anderson et al., 1994)

\section{Figure 1: Customer Satisfaction Index Model}

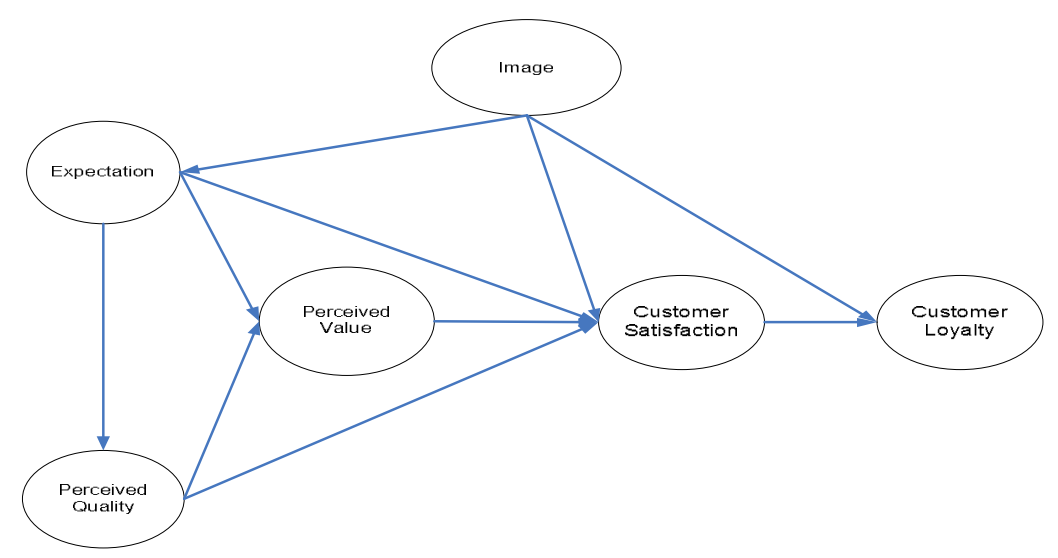

\section{Perceived Quality}

PQ is the served market's evaluation of recent consumption experience. This construct evaluates customization and reliability of a given product or service. Customization is the degree to which a product or service meets a customer's requirements, and reliability is the degree to which firm's offering is reliable, standardized, and free from deficiencies. PQ is expected to have a positive effect on PV and customer satisfaction (Fornell et al.,1996), and to be positively affected by image (Andreassen and Lindestad, 1998).

\section{Perceived value}

$\mathrm{PV}$ is the perceived level of product quality relative to the price paid by customers. PV is the rating of the price paid for the quality perceived and a rating of the quality perceived for the price paid. PV structure provides an opportunity for comparison of the firms according their price-value ratio. In the ECSI model, PV is expected to be positively affected by PQ, and it has a positive impact on satisfaction.

\section{Customer Satisfaction}

The index indicates how much customers are satisfied, and how well their expectations are met. This construct evaluates overall satisfaction level of customers, fulfillment of their expectations, and company's performance versus the ideal provider.

\section{RESEARCH METHODOLOGY}

\section{Survey Setting}

A case study method was used to collect the required data on the underlying dimensions of the research model. Turk Telekom Company which is the largest telecommunication company in Turkey was chosen as an ideal research setting in Turkey. Data were gathered from a face-to-face survey. Although the sample frame was the entire Turk Telekom customers, the sample of customer responses was drawn from five central districts of Istanbul. The survey was conducted to 280 Turk 
Telekom customers in 2009. The eligible respondents were those who qualify by recent experience as the purchaser and user of fixed line PSTN or broadband internet users. Among all collected data set, 266 were found satisfactory for data analysis. Occasional missing data on variables was handled by replacing them with the mean value.

\section{Survey Instrument}

The ECSI model consists of the aforementioned constructs which are based on well-established theories and approaches in customer behavior. The constructs of the ECSI model are unobservable (latent) variables indirectly described by a block of observable variables which are called manifest variables or indicators. The constructs and their observable items are given in Table 3 . The use of multiple questions for each construct increases the precision of the estimate, compared to an approach of using a single question.

A survey, developed to measure the manifest variables, was prepared in Turkish language, and the first draft was issued to 30 individuals to ensure that the wording, format, and sequencing of questionnaire appropriate. Feedback from this study indicated that some questions were ambiguous, difficult to understand, or irrelevant for telecommunication sector. The final questionnaire contained 19 questions pertaining to the CSI. A five-point measurement scale was used where 1 expresses a very negative point of view and 5 expresses a very positive.

\section{Reliability and Validity Protocols}

To insure reliability and validity of the measures (i.e. internal consistency and convergentdiscriminant validity respectively) as suggested by Gerbring and Anderson (1988) and Churchill (1979), the data were subjected to confirmatory factor analysis (CFA) within the causal modeling Lisarel framework. This procedure is preferable to exploratory factor analysis (EFA) in that it is a causal indicator model that requires a priori specifications of factor structure and allows for the specification of measurement errors (Venkatraman, 1989).

\section{Table 3: The latent variables and their observable indicators in the CSI Model}

\begin{tabular}{|c|l|}
\hline Latent variables & Observable (manifest) variables \\
\hline \multirow{4}{*}{ Image (IM) } & IM1: being reliable \\
& IM2: being professional \\
& IM3: customer relations \\
& IM4: innovative and forward looking \\
& IM5: adding value to user (prestige) \\
\hline \multirow{3}{*}{ Expectations (EXP) } & EXP1: expectations for fulfillment of personal need \\
& EXP2: expectations for overall quality \\
& EXP3: expectations for product quality \\
& PQ1: overall quality \\
& PQ2: product quality (technical) \\
& PQ3: service quality \\
& PQ4: customer services \\
& PV1: price/performance \\
& PV2: performance/price \\
\hline \multirow{2}{*}{ PQ } & CSI1: Compare with ideal \\
& CSI2: fulfillment of expectations \\
\hline \multirow{2}{*}{ CSI } & CL1: repurchase intention \\
\cline { 2 - 3 } & CL2: recommendation to others \\
\cline { 2 - 3 } & CL3: price tolerance \\
\hline \multirow{2}{*}{ CL } &
\end{tabular}




\section{DATA ANALYSIS AND RESULTS}

The analysis used in this study is undertaken in two stages. In the first stage, the overall reliability and validity of CSI Model in Turk Telekom Company is measured. In the second stage, we measure the relationships among constructs using the covariance based Structural Equation Model. These steps are discussed in the following subsections.

\section{Unidimensionality and Convergent Validity}

CFA was used on the collected data to evaluate the unidimensionality of each of the six dimensions of ECSI Model. Table 4 summarizes the results of this analysis.

\begin{tabular}{|l|c|c|c|c|c|c|c|c|c|c|}
\hline Construct & $\begin{array}{c}\text { Number of indi- } \\
\text { cators }\end{array}$ & $\begin{array}{c}\text { Chi- } \\
\text { square }\end{array}$ & df & $\begin{array}{c}\text { p- } \\
\text { value }\end{array}$ & GFI & AGFI & CFI & TLI & AVE & alpha \\
\hline IM & 5 & 7,331 & 6 & 0,291 & 0,99 & 0,96 & 0,99 & 0,99 & 0,51 & 0,860 \\
\hline EXP & 3 & 0,608 & 1 & 0,436 & 0,99 & 0,99 & 1,00 & 1,00 & 0,55 & 0,838 \\
\hline PQ & 4 & 0,049 & 2 & 0,976 & 1,00 & 0,99 & 1,00 & 1,01 & 0,67 & 0,905 \\
\hline PV & 2 & - & - & - & - & - & - & - & - & 0,916 \\
\hline CSI & 2 & - & - & - & - & - & - & - & - & 0,826 \\
\hline CL & 3 & - & - & - & - & - & - & - & - & 0,851 \\
\hline
\end{tabular}

Note: - CFA results cannot be obtained due to inadequate number of variables constituting this dimension.

Results provide the following model statistics for the assessment of goodness-of-fit: chi-square statistics, its associated degrees of freedom, p-value of significance, GFI, AGFI, CFI, and TuckerLewis index. One can conclude that each of the 3 dimensions achieves unidimensionality and convergent validity at monomethod levels of analysis. To exemplify, six items constituting the image dimension were subjected to CFA using the AMOS computer program. The chi-square statistic was 7,331 (degrees of freedom $=6, p>0.05$ ), with the chi-square/df ratio having a value of 1,222 , which is less than 2.0 (it should be between 0 and 3 with lower values indicating a better fit). The goodness -of-fit index (GFI) was 0.990 and the adjusted goodness-of-fit (AGFI) index was 0.966. These scores are very close to 1.0 (a value of 1.0 indicates perfect fit). The comparative fit index (CFI) was 0.998 , while the Tucker-Lewis coefficient (TLI) was 0.994. All indices are close to a value of 1.0 in CFA indicating that the constructs provide good support for the factor structure.

As is evidenced by the chi-square statistic with the associated degrees of freedom, the p-value of significance, GFI, AGFI, CFI, and TLI (Tucker Lewis Index) provided in Table 4 that measure goodness-of-fit, all of the analyzed dimensions of service quality are unidimensional, having strong convergent validity.

Convergent validity is the extent to which indicators of an ECSI construct converge or share a high proportion of variance in common. Table 4 also shows that most of the fit indices are within the acceptable range for each construct. This provides first-hand support for reliability and convergent validity of the constructs. We further looked at the significance of individual factor loadings of each item. All the individual factor loadings were found to be highly significant, giving support to convergent validity. We also calculated the average variance extracted (AVE) for each construct. These values are shown in Table 4. The values of AVE were higher than the recommended value of 0.50 , providing further support to convergent validity of constructs. The standardized regression weights for all variables constituting each dimension were also found to be significant $(\mathrm{p}<0.01)$.

\section{Reliability}

The reliability of the scales is related to the homogeneity of their items. It is a measure of the ability to produce the same results on repeated trials. Cronbach's alpha is commonly used to measure inter- 
nal consistency of the scales. It is based on the average correlation between items within a test. Cronbach's alpha is calculated for each scale. Table 4 lists Cronbach's alpha values of the scales developed. All the construct measures of are over 0.80 , thus exhibiting a satisfactory level of construct reliability. This establishes the internal consistency of the dimensions being studied and is reliable for this research.

\section{The Path Model}

Structural Equations Modeling (SEM) using AMOS 4.0, a software program that is a part of the Statistical Package for Social Sciences (SPSS) was used on the data set to test the causal relationships specified in the model as shown in Figure 1. For example, the causal relationships among constructs were explored and tested. The problem of missing data across the sample of 266 respondents was small at a calculated value of less than one percent. In these situations, the mean value of the variable was used. Model fit determines the degree to which the structural equation model fits the sample data. The commonly used model fit criteria are chi-square $\left(\chi^{2}\right)$, goodness of fit index (GFI), adjusted goodness of fit index (AGFI) and root mean square residual (RMS) (Schumacker and Lomax, 1996).

The goodness-of-fit indices for the path model [Satorra-Bentler $\chi^{2}=261.31$ with $\mathrm{df}=139$; GFI $=$ 0.91 ; $\mathrm{AGFI}=0.887$; TLI $=0.953 ; \mathrm{CFI}=0.962 ; \mathrm{RMR}=0.040]$ are well within the generally accepted limits, indicating a good fit to the data.

The standardized regression weights for all variables constituting each dimension which is shown in Table 5 were also found to be significant at 0.01 level.

\section{Table 5. Standardized Regression Weights}

\begin{tabular}{|c|c|c|c|}
\hline Latent variable & Manifest variable & Regression weight & t-value* \\
\hline IM & IM6 & 0,669 & - \\
\hline IM & IM5 & 0,739 & 10,383 \\
\hline IM & IM4 & 0,686 & 10,606 \\
\hline IM & IM2 & 0,731 & 10,16 \\
\hline IM & IM1 & 0,794 & 10,909 \\
\hline EXP & EXP3 & 0,657 & - \\
\hline EXP & EXP2 & 0,74 & 10,139 \\
\hline EXP & EXP1 & 0,709 & 9,801 \\
\hline PQ & PQ4 & 0,777 & 14,709 \\
\hline PQ & PQ3 & 0,847 & 16,171 \\
\hline PQ & PQ2 & 0,845 & - \\
\hline PQ & PQ1 & 0,845 & 16,634 \\
\hline PV & PV2 & 0,913 & - \\
\hline PV & PV1 & 0,926 & 17,944 \\
\hline CSI & CSI3 & 0,747 & - \\
\hline CSI & CSI2 & 0,745 & 12,308 \\
\hline CL & CL3 & 0,684 & - \\
\hline CL & CL2 & 0,882 & 12,659 \\
\hline CL & CL1 & 0,891 & 12,733 \\
\hline
\end{tabular}

Note: - Fixed for estimation; *all values are significant at the 0.01 level

Figure 2 presents inner regression weights for the structural relationships between causal paths based on the structural equation modeling technique. The results show that seven parameter estimates out of ten were found to be statistically significant. 


\section{Figure 2: The Results of the Path Analysis}

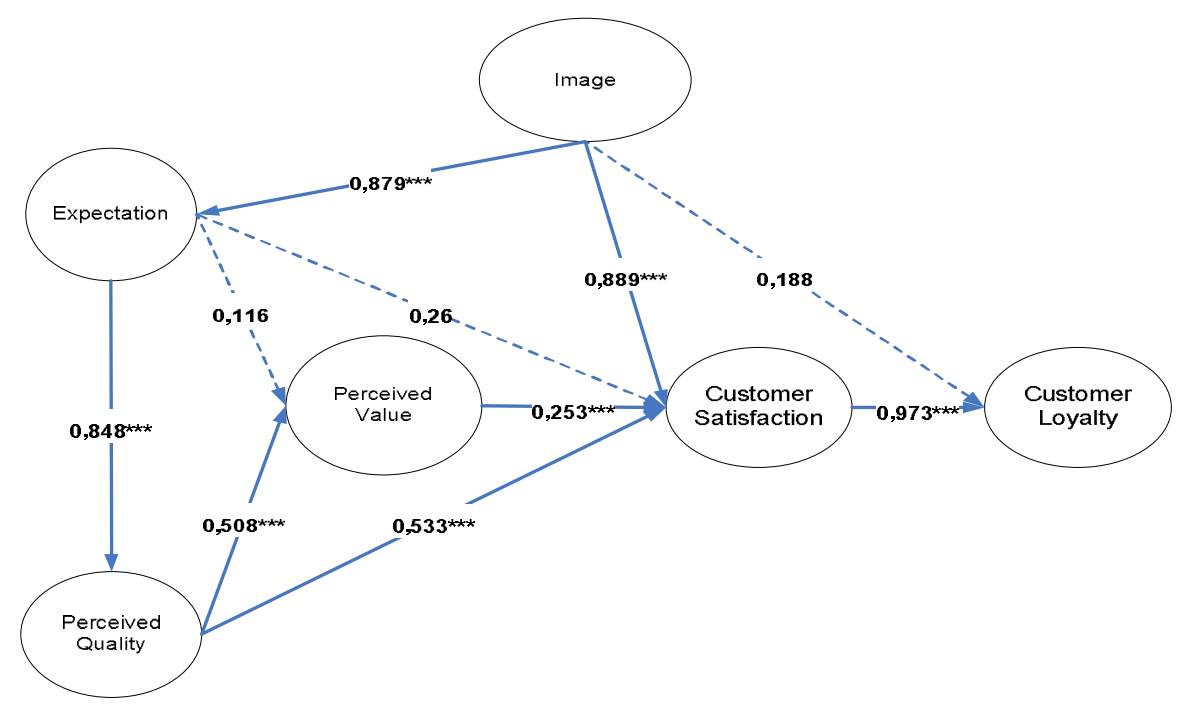

Note: $* * *$ values are significant at 0.01

\section{CONCLUSION}

In this study, we examined the relationship among the constructs of the customer satisfaction index model in Turk Telekom Company in Turkey. The covariance based structural equation modeling technique was used for testing the framework of the relationship among the constructs.

As we can see from figure 2, the analysis results show that image of the company has a positive and significant impact on customer expectation and customer satisfaction. As it is mentioned above, image refers to the brand name and the kind of associations customers get from the product/company. Image is one of the most important components of the customer satisfaction model. For the companies, image is a result of being reliable, professional and innovative, having contributions to society, and adding prestige to its customers. Although, Turk Telekom Company retains its dominant position in Turkey's fixed line market, there is a huge competition in the mobile market in Turkey.

On the other hand, we investigated the impact of the four constructs, which are named customer expectation, customer value, perceived quality, and image of the company, on the customer satisfaction. Image of the company, perceived value and perceived quality have positive and significant impact on customer satisfaction. Image of the company has the highest impact on customer satisfaction as a score of 0.889 . The second important factor was perceived quality. Perceived quality construct evaluates customization and reliability of a given product or service.

The results also revealed that customer satisfaction was significantly related to loyalty. In a similar vein, a strong and positive relationship has also been found between perceived quality and perceived value.

Finally, no support has been found between customer expectations and perceived value, image and customer satisfaction, and customer expectations and customer satisfaction constructs. 
In addition that the highest score among constructs was found between customer satisfaction and customer loyalty as a score of 0.973 . For the most of the findings reported in this study are consistent with the earlier research related to the customer satisfaction model. 


\section{REFERENCES}

Anderson, E.W., Fornell, C. and Lehmann, D.R. (1994) "Customer satisfaction, market share, and profitability: Findings from Sweden", Journal of Marketing, Vol 58, pp. 53-66.

Andreassen, T.W. and Lindestad, B. (1998) "The effects of corporate image in the formation of customer loyalty", Journal of Service Marketing, Vol 1, pp. 82-92

Aydin, S. and Ozer, G. (2005) "National customer satisfaction indices: an implementation in the Turkish mobile telephone market", Marketing Intelligence and Planning, Vol 23 No. 5, pp. 486-504

Chien, T.K., Chang, T.H. and Su, C.T. (2002), "Did your efforts really win customers' satisfaction?", Industrial Management \& Data Systems, Vol. 103 No. 4, pp. 253-62.

Eklöf, J. and Westlund, A.H. (2000), "The European customer satisfaction index: Its background and the role of private concerns and public utilities" in Fabris, G., Rolanda, S. (Eds.), La customer satisfaction nel settore pubblico, Franco Angeli Publishers, Milano

Fornell, C, Johnson, M.D., Anderson, E.W., Cha, J., and Bryant, B.E. (1996) "The American Customer Satisfaction Index: Nature, Purpose and Findings" Journal of Marketing, Vol 60, pp. 7-18

Fornell, C. (1992) “A national satisfaction barometer: The Swedish experience”, Journal of Marketing, Vol 56, pp. 6-21

Grigoroudis, E. and Siskos, Y. (2003) "A survey of customer satisfaction barometers: Some results from the transportation-communications sector", European Journal of Operational Research, Vol 152 No 2, pp. 334-353

Hirschman, A.O. (1970), "Exit, Voice, and Loyalty - Responses to Declines in Firms, Organizations and States", Harvard University Press, Cambridge

Johnson, M.D., Gustafsson, A., Andressen, T.W., Lervik, L. and Cha, J. (2001) "The Evolution and Future of National Customer Satisfaction Index Models", Journal of Economic Psychology, Vol 22 No 2, pp, 217-245

Li, B., Riley, M.W., Lin, B. and Qi, E. (2006), “A comparison study of customer satisfaction between the UPS and FedEx: an empirical study among university customers", Industrial Management \& Data Systems, Vol. 106 No. 2, pp. 182-99.

Martensen, A., Kristensen, K. and Grønholdt, L. (2000) "Customer satisfaction measurement at Post Denmark: Results of application of the European Customer Satisfaction Index methodology", Total Quality Management, Vol 11 No 7, pp. 1007-1015

Meyer, A. and Dornach, F. (1996) "The German Customer Barometer: Quality and SatisfactionYearbook of Customer Satisfaction in German 1995", German Marketing Association e.v. and German Post AG, Dusseldorf

Turkyilmaz A. and Ozkan C. (2007) "“"Development of a customer satisfaction index model: An application to the Turkish mobile phone sector ", Industrial Management and Data Systems, Emerald Publishing, Vol. 5, No. 107, pp. 672-687

TMME, (2006), Turkish Customer Satisfaction Index, www.tmme.org.tr 